This is the submitted version of the following article:

Israr M., Iqbal J ., Arshad A., Rani M., Gómez-Romero P., Benages R.. Graphene triggered enhancement in visible-light active photocatalysis as well as in energy storage capacity of (CFO) $1-x($ GNPs) $x$ nanocomposites. Ceramics I nternational, (2020). 46. : 2630 - . 10.1016/j.ceramint.2019.09.232,

which has been published in final form at https://dx.doi.org/10.1016/j.ceramint.2019.09.232 (c) https://dx.doi.org/10.1016/j.ceramint.2019.09.232. This manuscript version is made available under the CC-BY-NC-ND 4.0 license http://creativecommons. org/licenses/by-nc-nd/4.0/ 


\title{
Graphene Triggered Enhancement in Visible-Light Active Photocatalysis as Well As in Energy Storage Capacity of (CFO) ${ }_{1-x}\left(\right.$ GNPs) ${ }_{x}$ Nanocomposites
}

 \\ a. LNT, Department of Physics, Quaid-i-Azam University, Islamabad, Pakistan \\ b. Catalan Institute of Nanoscience and Nanotechnology, Autonomous University of Barcelona, Spain \\ c. Department of Physics, International Islamic University, Islamabad, Pakistan
}

*Corresponding author: javed.saggu@qau.edu.pk

\begin{abstract}
:
Cobalt ferrite-graphene nanoplatelets $\left((\mathrm{CFO})_{1-\mathrm{x}}(\mathrm{GNPs})_{\mathrm{x}}\right)$ nanocomposites are promising for efficient photocatalysis and high-performance supercapacitors. Multifunctional (CFO) $)_{1-\mathrm{x}}(\mathrm{GNPs})_{\mathrm{x}}$ nanocomposites prepared via facile chemical method have been investigated for their physiochemical characteristics like crystal structure, morphology, chemical composition, optical properties, infrared vibrational modes, photocatalytic and supercapacitor applications. Interestingly, the photocatalytic activity of CFO nanostructures has been improved significantly from $38.3 \%$ to $98.7 \%$ with the addition of graphene which can be attributed to control over recombination of charge carriers. It is also found that the specific capacitance of the prepared $(\mathrm{CFO})_{1-\mathrm{x}}(\mathrm{GNPs})_{\mathrm{x}}$ nanocomposite electrode at $0.5 \mathrm{Ag}^{-1}$ is three times higher than that of only $\mathrm{CFO}$ based electrode which could be due to the conducting nature of graphene nanoplatelets (GNPs). The enhanced photocatalytic and improved electrochemical characteristics suggest the effective use of prepared nanocomposites in water purification and supercapacitor nanodevices.
\end{abstract}

Keywords: Nanocomposites; electron-hole recombination; photocatalysis; supercapacitors

\section{Introduction}

The organic contaminants in wastewater pose a great threat to the human wellbeing and environmental safety, due to their highly toxic nature. Therefore, the development of efficient technologies for fast water purification is need of the day [1]. Among various technologies, the 
visible light driven photocatalysis is the most promising and cost-effective technique for water purification. Over the past few years, the ferrite nanostructures have been used as photocatalyst because of their excellent visible light response and easy magnetic separation [2]. However, these magnetic nanostructures have a great challenge to be used in various applications due to fast charge recombination, poor dye adsorption, and agglomeration [3]. In order to address these issues, the addition of carbon derivatives such as graphene as supportive constituents to the ferrites could be a possible solution [4]. Apart from the high conductivity and suitable work function of graphene, the strong ability of graphene to accept electrons from ferrites plays a significant role to enhance the photocatalytic performance. Moreover, the graphene can also prevent the agglomeration of magnetic ferrites due to its nonmagnetic nature and availability of large surface area for interfacing [5]. Various ferrites composited with different forms of graphene (e.g. graphene oxide (GO) and reduced graphene oxide (rGO)), such as reduced graphene oxide, graphene oxide etc. have been extensively-explored widely investigated and employed as photocatalyst for photocatalysis because of their high photocatalytic activities [610]. However, the oxygen containing functional groups oxygen moieties present in GO-or rGO rGO or GO act as defect states and lower the conductivity of graphene. These oxygen based defects lead towards ow low photocatalytic efficiency [11]. Therefore, pure graphene would be a better choice to boost the performance of the graphene based photocatalytic nanocomposites.

The need of cost effective and eco-friendly storage devices of renewable energy is one of the major challenge in the energy sector. Supercapacitors are considered to be promising for energy storage; because of their Supercapacitors are thought to be potential devices for the storage of electrical energy; due to their rapid charge discharge efficiency and long cyclic performance $[12,13]$. These are highly desired in hybrid electric vehicles, mobile electronic devices and smart electricity grids [14]. Due to good pseudo capacitance and better thermal stability, the ferrites have been used traditionally as electrode materials in energy devices. However, their high resistivity and agglomeration leads towards poor rate performance with low cycling stability which limit their use in storage devices [15]. The carbon-based nanomaterials such as graphene has longer cyclic life and more rapid charge discharge efficiency. Therefore, the addition of conductive graphene might be the better solution to overcome the limitations of ferrites [16-19]. 
This work has been focused on the enhancement of visible light driven photocatalytic response and improvement of electrochemical properties of $(\mathrm{CFO})_{1-\mathrm{x}}(\mathrm{GNPs})_{\mathrm{x}}$ nanocomposites. The study presents the degradation of methylene blue (MB) dye found in textile wastewater using $(\mathrm{CFO})_{1-\mathrm{x}}(\mathrm{GNPs})_{\mathrm{x}}$ nanocomposites under visible light irradiation. The electrochemical performance of the prepared $(\mathrm{CFO})_{1-\mathrm{x}}(\mathrm{GNPs})_{\mathrm{x}}$ nanocomposites has also been investigated under different conditions.

\section{Experimental}

\subsection{Preparation of CFO and (CFO) $)_{1-\mathrm{x}}(\mathrm{GNPs})_{\mathrm{x}}$ nanocomposites}

Optimized parameters have been used for synthesis of CFO nanostructures and (CFO) $)_{1-\mathrm{x}}(\mathrm{GNPs})_{\mathrm{x}}$ nanocomposites. In typical procedure, $\mathrm{FeCl}_{3} \cdot 6 \mathrm{H}_{2} \mathrm{O}(0.4 \mathrm{M})$ and $\mathrm{CoCl}_{2} \cdot 6 \mathrm{H}_{2} \mathrm{O}(0.2 \mathrm{M})$ were dissolved in $100 \mathrm{~mL}$ distilled water. Then cetrimonium bromide (CTAB) (0.1 g) was added to the mixture and sonicated was dissolved in the mixed solution under ultra-sonication for 10 minutes. $\mathrm{NaOH}(6 \mathrm{M})$ solution was prepared in $50 \mathrm{~mL}$ distilled water in a separate beaker and heated at $80^{\circ} \mathrm{C}$. The mixed aqueous solution of $\mathrm{FeCl}_{3} \cdot 6 \mathrm{H}_{2} \mathrm{O}(0.4 \mathrm{M})$ and $\mathrm{CoCl}_{2} \cdot 6 \mathrm{H}_{2} \mathrm{O}(0.2 \mathrm{M})$ mixture solution was added dropwise was added dropwise to the stock solution of $\mathrm{NaOH}$ and CTAB stock solution. The mixture was. The reaction mixture was kept at optimized $80^{\circ} \mathrm{C}$ for two hours under constant stirring. The precipitates were collected after washing many times with ethanol and distilled water. The precipitates were collected after washing with distilled water and ethanol several times and then dried at $100^{\circ} \mathrm{C}$ for 24 hours to get powdered sample [20]. (CFO)1х(GNPs) $)_{x}$ nanocomposites with different GNPs content $(25,50,75$ wt. \%) were synthesized. A typical experimental procedure for the preparation of $(\mathrm{CFO})_{0.75}(\mathrm{GNPs})_{0.25}(25 \mathrm{wt}$. \% GNPs) nanocomposites is given as follows: $25 \mathrm{wt} . \%$ of GNPs were mixed with CFO nanostructures and the mixture was dispersed in $30 \mathrm{~mL}$ ethanol. The suspension was then sonicated for 2 hours in ultrasonic bath and dried at $60^{\circ} \mathrm{C}$ for 12 hours and dried for 12 hours at $60^{\circ} \mathrm{C}$ in an oven. The obtained sample was further annealed at $500^{\circ} \mathrm{C}$ for 2 hours in $\mathrm{N}_{2}$ atmosphere to obtain (CFO) 1- $^{-}$ ${ }_{x}(\text { GNPs })_{x}$ nanocomposite [21]. Same procedure has been adapted for fabrication of other nanocomposites with desired compositions.

\subsection{Characterizations}


XRD data was obtained using with the help of a Malvern PANalytical X'pert PRO MPD $\mathrm{Cu} \mathrm{K} \mathrm{K}_{\alpha}(\lambda=1.5406 \AA)$ radiation-source. Surface morphology of the samples was studied using TEM (Thermo Fisher Tecnai G2 F20). FTIR spectra were recorded using FTIR spectrometer (Tensor 27 FT-IR Spectrometer (Bruker)). Optical absorption spectroscopy of the samples was carried out by UV-visible spectrophotometer (UV-3600 spectrophotometer, Shimadzu Co., Japan). Roøm temperature XPS measurements characterizations were performed carried out at room temperature with a using SPECS PHOIBOS 150 analyzer (SPECS GmbH, Berlin, Germany) at $5 \times 10^{-10}$ mbar base pressure, using monochromatic Al Kaexcitation source (1486.74 eV). The PL spectra were collected using Cary Eclipse Fluorescence Spectrophotometer (Agilent).

\subsection{Measurements of photocatalytic activity performance}

All the photocatalytic experiments the experiments for measuring degradation performance have been earried out performed under visible light illmmination irradiation at room temperature. To evaluate the photocatalytic performance, a $100 \mathrm{~mL}$ of $20 \mathrm{mg} \mathrm{L}^{-1}$ of dye aqueous solution was taken from the stock solution with addition of $25 \mathrm{mg}$ photocatalyst. $1 \mathrm{ml}$ of $\mathrm{H}_{2} \mathrm{O}_{2}$ was added to this solution. Adsorption-desorption equilibrium between the catalyst and dye was achieved by stirring the reaction mixture for $60 \mathrm{~min}$ in dark. A xenon lamp (500 W) was used as a light source to irradiate the samples. About $4 \mathrm{~mL}$ of the test solution was taken at regular time intervals. The absorbance of MB during the degradation process was measured using UV-visible spectrophotometer.

\subsection{Electrochemical measurements}

Electrochemical performances characteristics of the prepared electrode materials electrodes have been tested on Biologic VMP3 potentiostat using cyclic voltammetry (CV) and galvanostatic charge-discharge (GCD) and electrochemical impedance spectroscopy (EIS)in $0.5 \mathrm{M} \mathrm{K}_{2} \mathrm{SO}_{4}$ aqueous electrolyte solution as an electrolyte. The working electrodes were fabricated by mixing $80 \%$ active material with $10 \%$ PVDF and $10 \%$ carbon super-P in Nmethyl-2-pyrrolidone to get uniform sturry paste. Finally, the slurry paste was applied to aluminum foil by dector blade method and was dried in vacumm oven for $24 \mathrm{~h}$ at $80^{\circ} \mathrm{C}$ under vacuum conditions. The electrochemical properties were measured with standard two-electrode 
symmetric cell in a 3-way Teflon Swagelok cell using identical electrodes with glass microfiber separator.

\section{Results and discussions}

\subsection{Structural analysis}

X-ray powder diffractograms of pristine $\mathrm{CFO}$ and $(\mathrm{CFO})_{1-x}(\mathrm{GNPs})_{\mathrm{x}}$ eempesites composite samples are shown in Fig.1. The characteristic peaks in the diffraction patterns of $\mathrm{CFO}$ and $(\mathrm{CFO})_{1-x}(\mathrm{GNPs})_{x}$ composites ean be are well indexed to matched with the (220), (311), (400), (511), (440) and (533) planes of cubic spinal phase crystal structure of CFO as reported in JCPDS No. 22-1086 [22]. The relatively high intensities of diffraction peaks clearly depict that prepared CFO sample is highly crystalline. There is no XRD peaks related to impurities or other extra phases in the diffraction pattern. These results demonstrate that the prepared CFO and $(\mathrm{CFO})_{1-x}(\mathrm{GNPs})_{\mathrm{x}}$ composites samples are in their pure phases. Furthermore, the peak at $2 \theta=$ $26.3^{\circ}$ in $(\mathrm{CFO})_{1-x}(\mathrm{GNPs})_{\mathrm{x}}$ samples corresponds to (002) characteristic plane of GNPs which confirms the successful formation of the desired composites. It is also observed that there is slight shift in diffraction planner peaks with systematic change in composition of composites, which is assigned to the interfacing of both constituents and the formation of structural defects. 


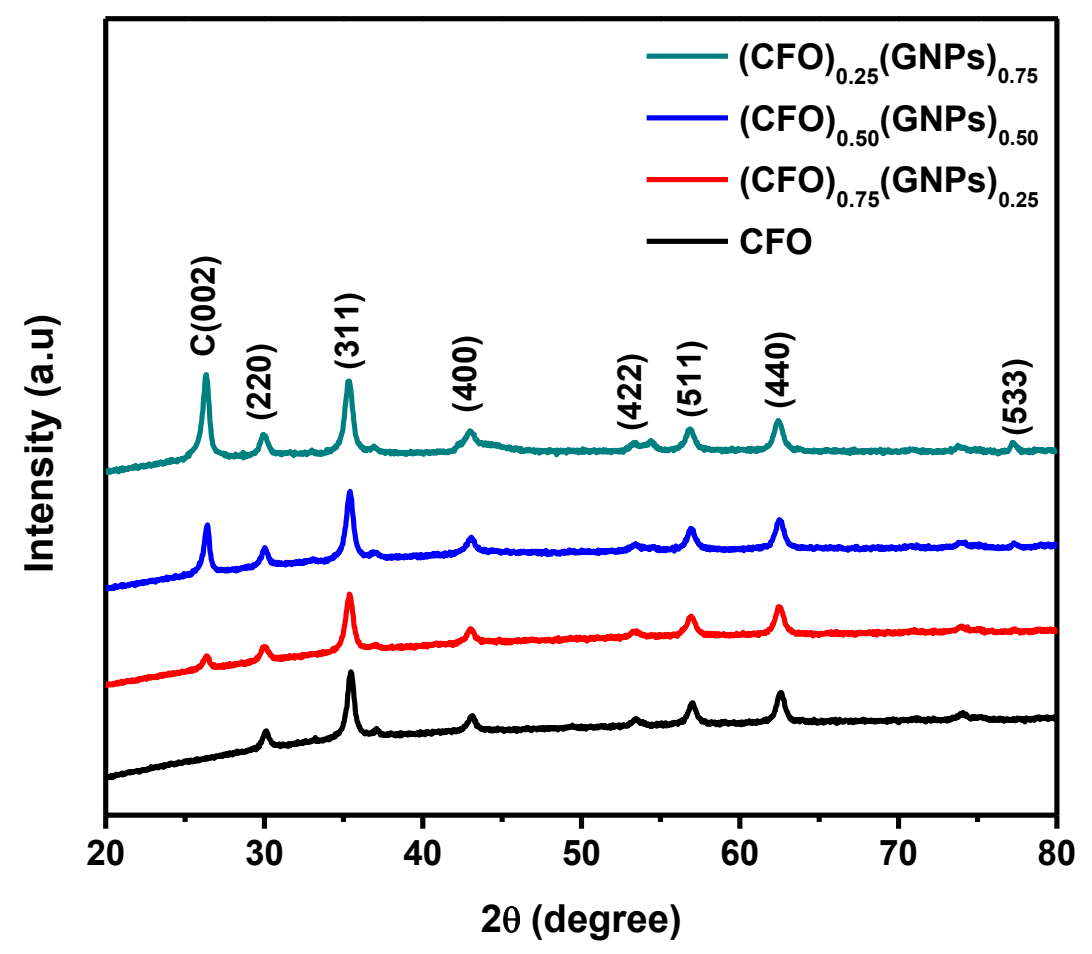

Fig.1: $\mathrm{XRD}$ patterns of $(\mathrm{CFO})_{1-\mathrm{x}-}(\mathrm{GNPs})_{\mathrm{x}}$ samples

\subsection{Morphological study}

The morphology of prepared CFO and (CFO) $)_{1-x}(\mathrm{GNPs})_{\mathrm{x}}$ samples has been examined using TEM. In pristine CFO sample (Fig.2 (a)), the shape of the nanostructures is quasi cubic with an average size in the range of $10 \mathrm{~nm}-31 \mathrm{~nm}$. Fig. 2(b-d) depicts uniform attachment of CFO nanostructures with wrinkled GNPs which confirms the formation of the composite with well-defined interfacing. It is interesting to note that the agglomeration of CFO nanostructures has been reduced significantly by incorporation of GNPs which might be attributed to nonmagnetic nature and high surface area of GNPs. The HRTEM microstructural studies of nanostructures further confirms the high crystallinity of the CFO nanostructures as given in inset of Fig. 2(a). The fringes with lattice spacing of $0.297 \mathrm{~nm}$ are assigned to (220) plan of CFO [23]. The observation obtained from HRTEM is also consistent with XRD results shown in Fig.1. 


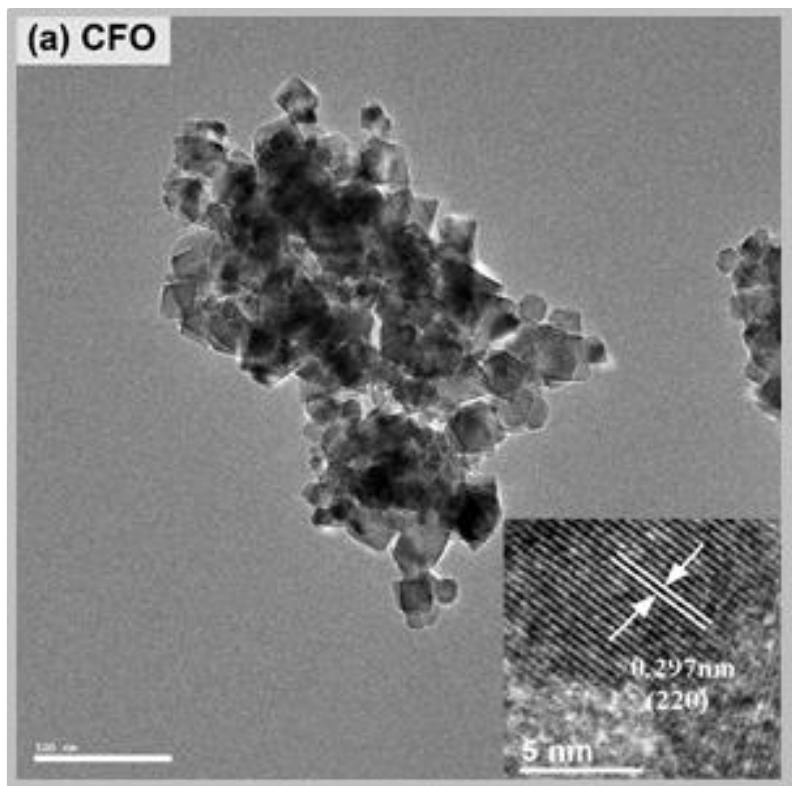

\section{(c) (CFO) $0.50(\mathrm{GNPs})_{0.50}$}

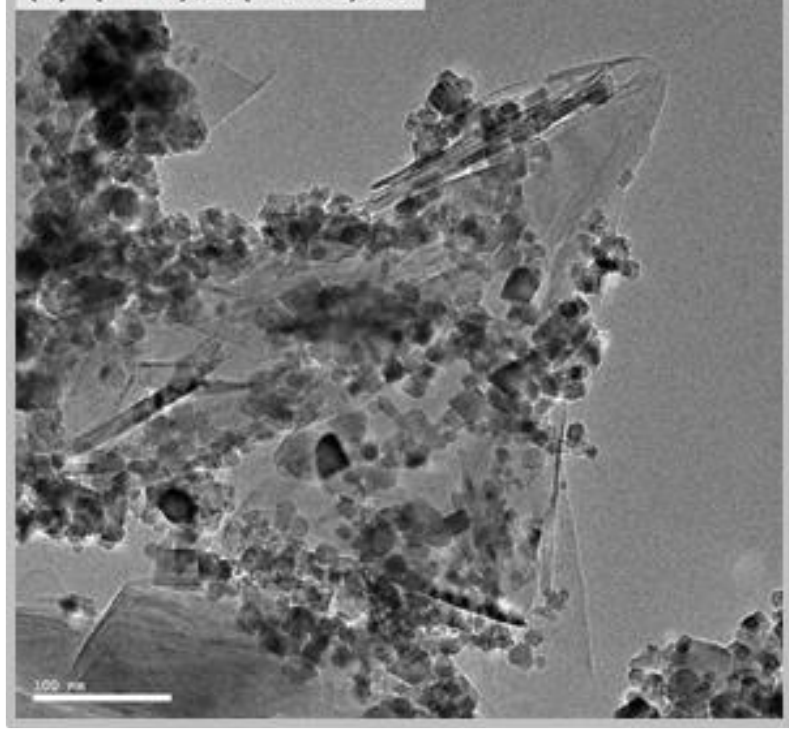

(b) (CFO) 0.75 (GNPs) 0.25

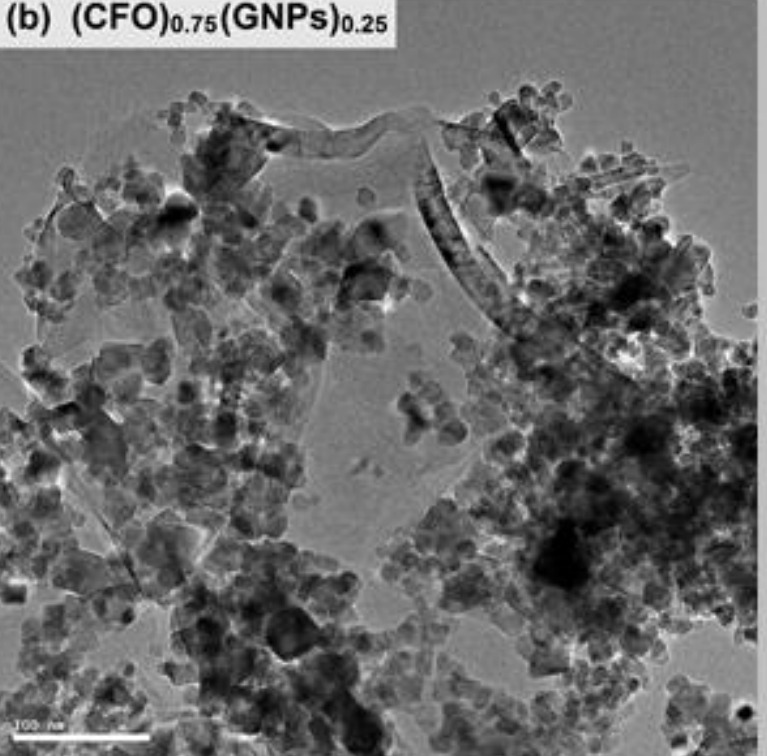

(d) (CFO) $_{0.25}$ (GNPs) $)_{0.75}$

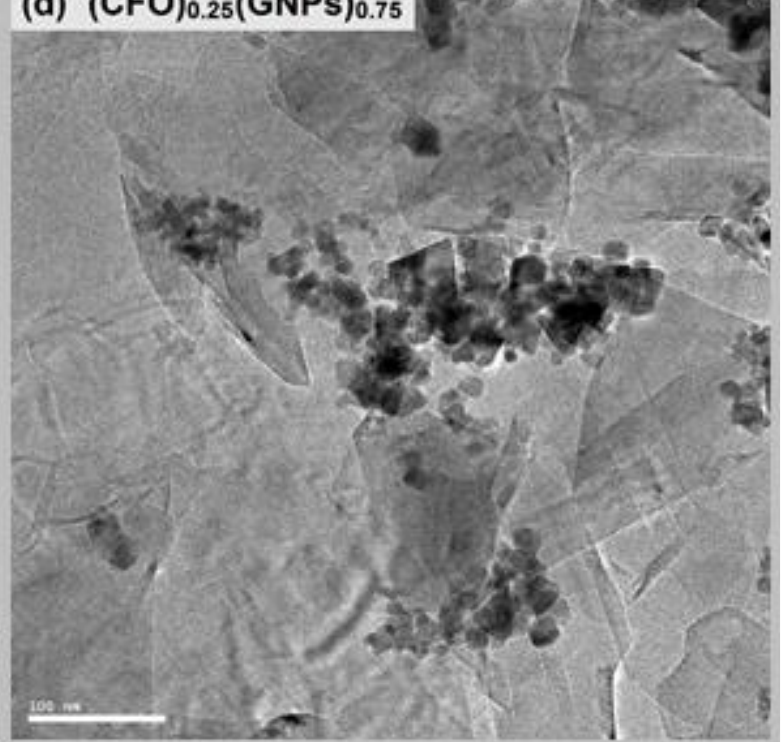

Fig.2: TEM micrographs of $(\mathrm{CFO})_{1-x}(\mathrm{GNPs})_{\mathrm{x}}$ samples (inset: HRTEM image of CFO)

\subsection{Vibrational Study}

FTIR spectroscopy has been used to explore the chemical structure of pure CFO nanostructures and $(\mathrm{CFO})_{1-x}(\mathrm{GNPs})_{\times}$nanocomposites as presented in Fig.3. The bands at $431 \mathrm{~cm}^{-1}$ 
and $560 \mathrm{~cm}^{-1}$ are attributed to $\mathrm{Co}-\mathrm{O}$ and $\mathrm{Fe}-\mathrm{O}$ symmetrical stretching vibrations respectively [24]. The band at $1639 \mathrm{~cm}^{-1}$ belongs to $\mathrm{C}=\mathrm{C}$ skeletal vibrations of GNPs and the band at 3400 $\mathrm{cm}^{-1}$ is assigned originates from $\mathrm{O}-\mathrm{H}$ stretching vibrations [25, 26]. There are no exygen containing functional groups oxygen moieties in the FTIR spectrum of GNPs and (CFO)1${ }_{x}(\mathrm{GNPs})_{\mathrm{x}}$ nanocomposite samples which confirm the purity of nanocomposites. This study further verifies the structural analysis of XRD.

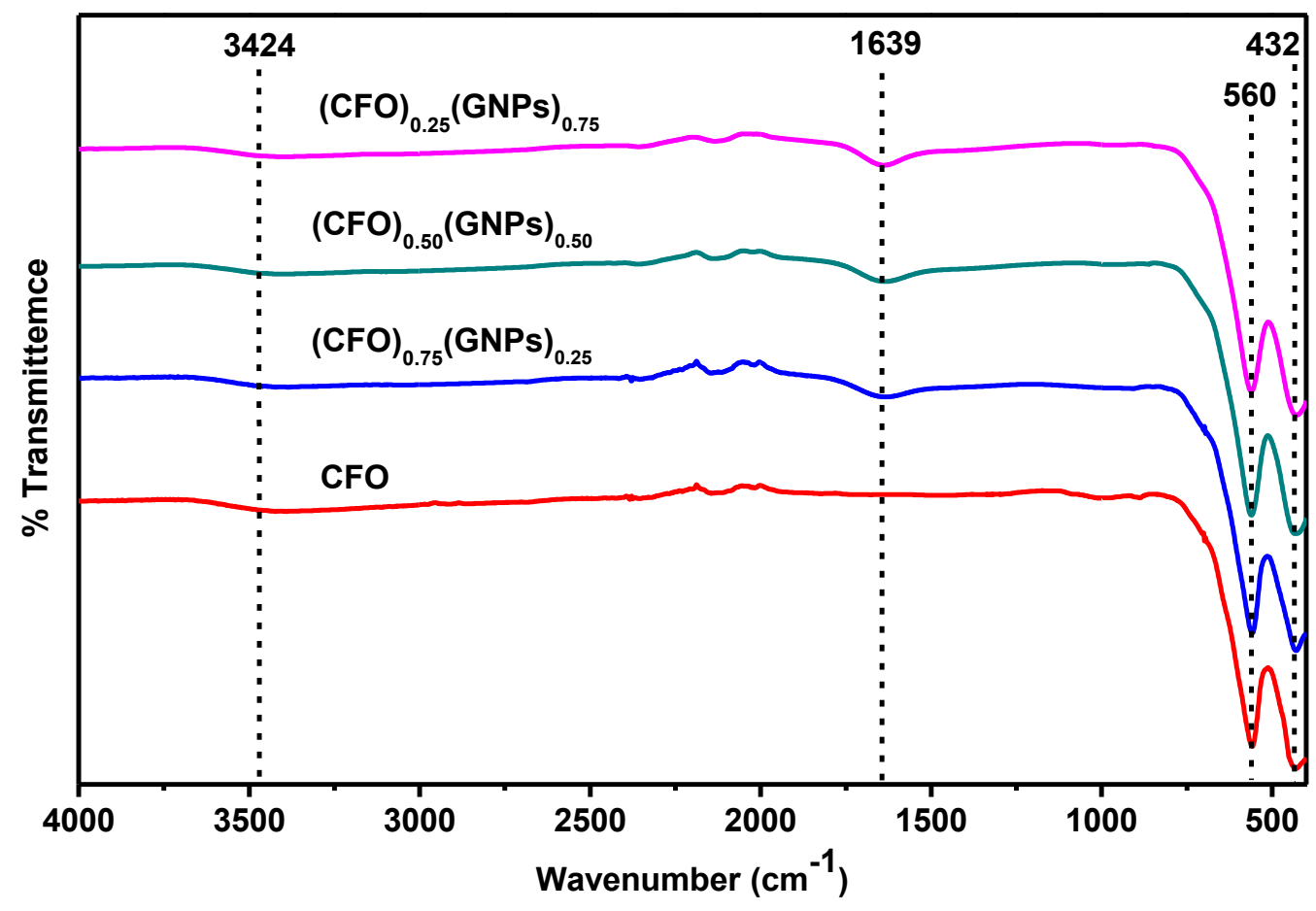

Fig.3: FTIR spectra of (CFO) $)_{1-x}(\mathrm{GNPs})_{\mathrm{x}}$ nanocomposites

\subsection{XPS analysis}

The valance oxidation state of different elements in materials plays important role to the change the basic science of host composites leading towards the formation of defects and impurities which may be responsible for control over electron hole recombination rates. The oxidation state and chemical compositions of elements in (CFO) $)_{1-\mathrm{x}}(\mathrm{GNPs})_{\mathrm{x}}$ nanocomposites have been checked using XPS spectroscopy at room temperature. The spectra of $(\mathrm{CFO})_{1-\mathrm{x}}(\mathrm{GNPs})_{\mathrm{x}}$ nanocomposites have carried out and typical results for $(\mathrm{CFO})_{1-\mathrm{x}}(\mathrm{GNPs})_{\mathrm{x}}[\mathrm{x}=0,0.25]$ are given in Fig 5(a). The two distinct peaks of $\mathrm{Co}$ at $780.8 \mathrm{eV}$ and $796.3 \mathrm{eV}$ in XPS spectrum of CFO are assigned attributed to Co $2 \mathrm{p}_{3 / 2}$ and Co $2 \mathrm{p}_{1 / 2}$, respectively [27]. The corresponding satellite peaks 
located at binding energies $786.6 \mathrm{eV}$ and $803.5 \mathrm{eV}$. The difference in binding, shape and positions of Co $2 p_{3 / 2}$ and Co $2 p_{1 / 2}$ in spectra with existence of satellite peaks depict that Co is $2+$ oxidation state in all prepared samples [28].However, there is slight shift in positions of both Co $2 p_{3 / 2}$ and Co $2 p_{1 / 2}$ peaks with GNPs addition incorporation towards the lower energy which is assigned to the formation of interfacial defect, associated with GNPs concentration.
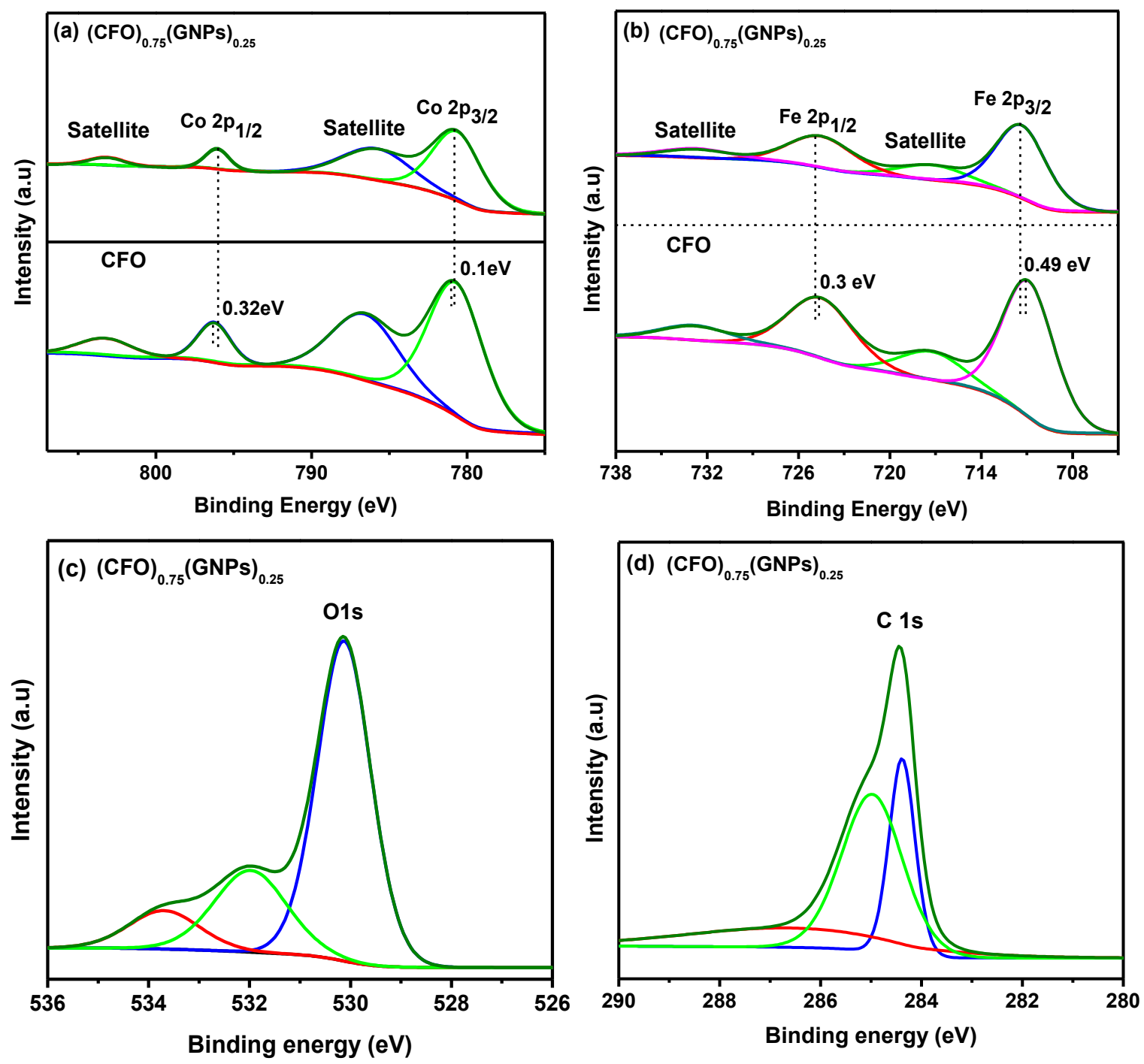

Fig. 4: XPS wide angle spectra for $(\mathrm{CFO})_{1-x}(\mathrm{GNPs})_{x}$ nanocomposites.

The peaks related to $\mathrm{Fe} 2 \mathrm{p}_{3 / 2}$ and $\mathrm{Fe} 2 \mathrm{p}_{1 / 2}$ are centered at $710.9 \mathrm{eV}$ and $724.7 \mathrm{eV}$ respectively, as shown in Fig 5(b). Two shake up satellites peaks at $718.8 \mathrm{eV}$ and $733.4 \mathrm{eV}$ confirm $\mathrm{Fe}^{3+}$ oxidation state of $\mathrm{Fe}[29]$. The peaks eorresponding related to $\mathrm{Fe} 2 \mathrm{p}_{3 / 2}$ and $\mathrm{Fe} 2 \mathrm{p}_{1 / 2}$ in $(\mathrm{CFO})_{1}$ - 
x(GNPs) nanocomposite $(25$ wt. \%) are shifted by $0.49 \mathrm{eV}$ and $0.3 \mathrm{eV}$ respectively, towards the higher energy. The slight shift in $\mathrm{Fe} 2 \mathrm{p}$ and Co $2 \mathrm{p}$ indicates the bonding and electronic interaction between GNPs sheets and CFO nanostructures [30]. Three deconvoluted peaks in wide angle XPS of O1s in $(\mathrm{CFO})_{1-\mathrm{x}}(\mathrm{GNPs})_{\mathrm{x}}(25 \mathrm{wt} . \%)$, are depicted in Fig.5(c). The maxima in spectra at 530.1, 531.9 and $533.7 \mathrm{eV}$ is attributed to metal-oxygen bond (M-O-M), hydroxyl groups $(\mathrm{M}-\mathrm{O}-\mathrm{H})$ adsorbed on the surface of the sample adsorbed on the sample surface and the surface adsorbed oxygen respectively [31]. The M-O-M peaks are slightly shifted toward lower energy in $(\mathrm{CFO})_{0.75}(\mathrm{GNPs})_{0.25}$ nanocomposites compared to that in $\mathrm{CFO}$, which possibly is because of the formation of $\mathrm{Fe}-\mathrm{O}-\mathrm{C}$ and $\mathrm{Co}^{-} \mathrm{O}-\mathrm{C}$ bonds between the $\mathrm{CFO}$ nanostructures and GNPs. This indicates attachment between CFO and the GNPs. The two resolved peaks in the $\mathrm{C} 1 \mathrm{~s}$ spectrum at $284.39 \mathrm{eV}$ and $285 \mathrm{eV}$ given in Fig.5 (d), can be assigned attributed to C C GNPs aromatic rings and $\mathrm{C} O$ bonds respectively [32]. The two resolved peaks at 284.39 and $285 \mathrm{eV}$ in the $\mathrm{C} 1 \mathrm{~s}$ spectrum show the presence of $\mathrm{C}=\mathrm{C}\left(\mathrm{sp}^{2}\right)$ and $\mathrm{C}-\mathrm{C}\left(\mathrm{sp}^{3}\right)$ bonds, respectively [Reference: La, D.D., et al., Fabrication of a GNP/Fe-Mg binary oxide composite for effective removal of arsenic from aqueous solution. ACS Omega, 2017. 2(1): p. 218-226.]

\subsection{Optical Characteristics}

The optical properties of (CFO) ${ }_{1-\mathrm{x}}(\mathrm{GNPs})_{\mathrm{x}}$ nanocomposites have been studied by comparing their UV-vis spectra as shown in Fig.5(a). It has been observed that pristine CFO as well the nanocomposites have shown efficient absorption in broad wavelength range including both UV and visible spectrum of light. The band gap energies for CFO nanostructures and (CFO) $)_{1-x}(\mathrm{GNPs})_{\mathrm{x}}$ nanocomposite have been calculated using well known Tauc's relation [33].

$$
(\alpha h v)^{n}=A\left(h v-E_{g}\right)
$$

Here $\alpha, h v, n, A, a n d E_{g}$ are absorption coefficient, photon energy, integer, absorption constant coefficient and band gap energy respectively. The band gap is obtained using $n=2$ for allowed direct transitions. The calculated band gap values from experimental spectra are $1.95 \mathrm{eV}, 1.83$ $\mathrm{eV}, \quad 1.68 \mathrm{eV}$ and $3.05 \mathrm{eV}$ for $\mathrm{CFO}, \quad(\mathrm{CFO})_{0.75}(\mathrm{GNPs})_{0.25}, \quad(\mathrm{CFO})_{0.50}(\mathrm{GNPs})_{0.50}$ and $(\mathrm{CFO})_{0.25}$ (GNPs) 0.75 samples as given in Fig. 4(b). It is interesting to note that the band gap is significantly tuned towards visible range with the increasing of GNPs content up to a certain extent i.e., 50 wt.\% which is indication of sample's application for visible light triggered 
photodegradation. This change in band gap as function of GNPs concentration is attributed to the hybridization between GNPs and CFO nanostructures [34]. The hybridization between GNPs and $\mathrm{CFO}$ nanostructures in the composite structures gives rise to the formation of strong Fe-O-C bonds. This chemical interaction introduces additional energy levels states between conduction and valence band of the composite material and as a result band gap energy reduces [35, 36]. However, it is also observed that there is an increase in bandgap energy for $(\mathrm{CFO})_{0.25}(\mathrm{GNPs})_{0.75}$ nanocomposites. This anomalies for higher concentration is due to Burstein-Moss effect arising from the high surface interactions of GNPs with CFO as compared with less concentration in other $(\mathrm{CFO})_{1-\mathrm{x}}(\mathrm{GNPs})_{\mathrm{x}}$ nanocomposites. This effect occurs, when electronic states at the bottom of conduction band of a semiconductor are fully populated. In this case, the electrons could flow from graphene into the conduction band of CFO, due to the difference in their Fermi levels. At higher graphene ratio, would allow more $\pi$-electrons to enter the conduction band of CFO nanostructures. As a result some states close to the conduction band of CFO are populated, and the Fermi level goes up into the conduction band, which causes blue shift in the band gap [37, $38]$.
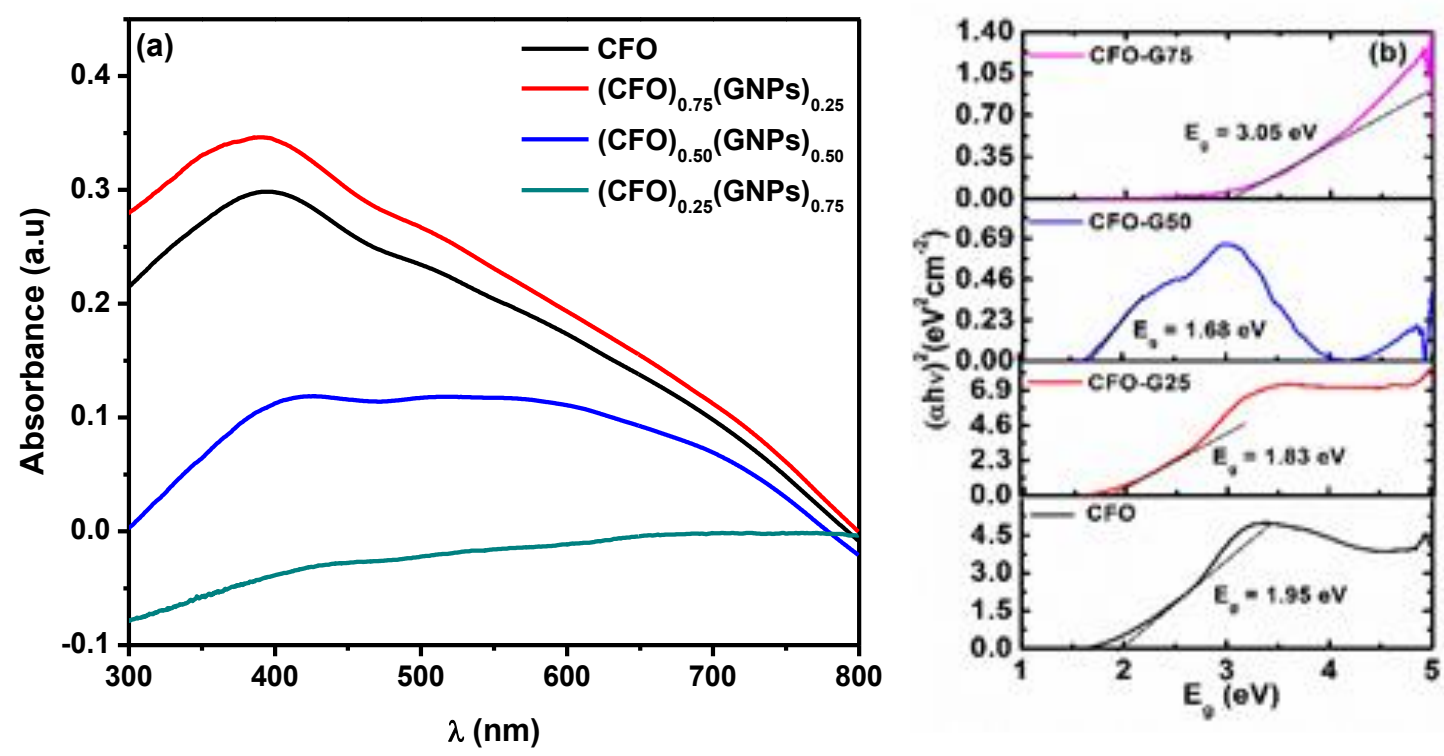

Fig.5: (a)UV-vis absorbance spectra of $(\mathrm{CFO})_{1-\mathrm{x}}(\mathrm{GNPs})_{\mathrm{x}}$ nanocomposites, (b) Tauc's plots of $(\mathrm{CFO})_{1-\mathrm{x}}(\mathrm{GNPs})_{\mathrm{x}}$ nanocomposites. 


\subsection{Luminescence properties}

The room temperature photoluminescence $(\mathrm{PL})$ spectra of $(\mathrm{CFO})_{1-\mathrm{x}}(\mathrm{GNPs})_{\mathrm{x}}$ nanocomposites is shown in Fig.6. It has been found that the PL intensity of nanocomposites is decreased with GNPs addition which suggests that the recombination of photo-generated $\mathrm{e}^{-} / \mathrm{h}^{+}$is sufficiently prevented as compared to that in pristine CFO nanostructures [39]. The electrons accepting ability and conductivity of $(\mathrm{CFO})_{1-x}(\mathrm{GNPs})_{\mathrm{x}}$ nanocomposites is higher than the $\mathrm{CFO}$ nanostructures, which is due to high electron affinity of graphene to delay $\mathrm{e}^{-/ h^{+}}$ recombination in nanocomposites. This behavior is very significant and useful for the application of CFO based nanocomposites in photocatalysis.

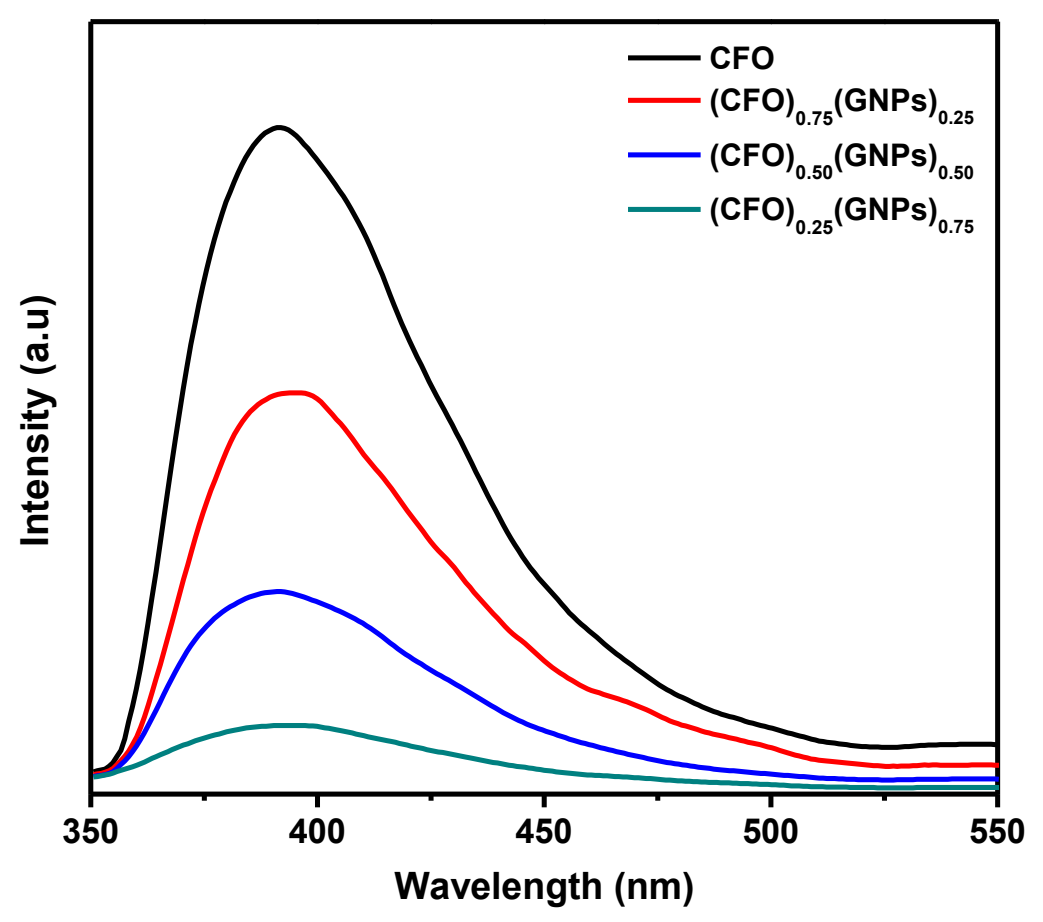

Fig. 6: $\mathrm{PL}$ spectra of $(\mathrm{CFO})_{1-\mathrm{x}}(\mathrm{GNPs})_{\mathrm{x}}$ nanocomposites

\section{Photocatalysis}

The degradation of organic pollutant particularly presence of methylene blue (MB) in textile waste via cost effective solar light triggered nanocomposites catalyst is one of recent demand in material science. Fig. 7(a)-(e) shows absorbance spectra of methylene blue (MB) in presence of $(\mathrm{CFO})_{1-\mathrm{x}}(\mathrm{GNPs})_{\mathrm{x}}(\mathrm{x}=0,0.25,0.50,0.75,1)$ as a function of time. The adsorption- 
desorption equilibrium between the catalyst and the dye has been achieved first $(\mathrm{t}=0 \mathrm{~min})$. It is clear from the Fig.7 (a)-(e) that concentration of the dye $\left(\mathrm{C} / \mathrm{C}_{0}\right)$ decreases with time for all samples. Fig.7(f) represents photo-degradation rates of GNPs, CFO and $\mathrm{CoFe}_{2} \mathrm{O}_{4}-\mathrm{GNPs}$ nanocomposites in the presence of visible irradiation at $25^{\circ} \mathrm{C}$. It is observed that the degradation efficiencies of individual GNPs and CFO nanostructures are $23.4 \%$ and $38.3 \%$ respectively in 120 min under visible light, which show very slow rate with less degradation process for MB pollutant. It has been interestingly found that the prepared nanocomposites $(\mathrm{CFO})_{0.75}(\mathrm{GNPs})_{0.25}$, $(\mathrm{CFO})_{0.50}(\mathrm{GNPs})_{0.50}, \quad(\mathrm{CFO})_{0.25}(\mathrm{GNPs})_{0.75}$ have $98.7 \%, 93.2 \%$ and $82.1 \%$ photocatalytic degradation under same condition respectively, which is almost three times then the individual CFO nanostructures degradation. The understanding of very high degradation rate for particular 25 wt.\% GNPs composition while decrease for other 50\% and $75 \%$ GNPs compositions with CFO can be attributed to the shielding effect caused by GNPs [40]. When the content of graphene is increased beyond certain limit, the active sites in the photocatalyst are covered by graphene nanoplates. Due to because of the limited access of visible light to the active sites of the photocatalyst, the photocatalytic reaction slows down, which causes to degrade the photocatalytic performance. The photocatalytic degradation mechanism of MB in these prepared nanocomposites can be explained using Photo-Fenton Reaction (PFR) process [41]. In this process, $\mathrm{Fe}^{3+} / \mathrm{Fe}^{2+}$ ion pairs are mutually converted through redox reactions occurring at the photocatalyst surface. During the reversible redox reaction process, active sites $\left(\mathrm{Fe}^{2+}\right)$ on the photocatalyst surface decompose $\mathrm{H}_{2} \mathrm{O}_{2}$ into reactive oxygen species (ROS) i.e. hydroxyls radicals $(\bullet \mathrm{OH})$ and hydroperoxyl radicals $(\bullet \mathrm{OOH})$. These ROS then play an important role to maximum oxidize the hazardous $\mathrm{MB}$ molecules to form nontoxic $\mathrm{CO}_{2}$ and $\mathrm{H}_{2} \mathrm{O}$ in final products [42]. Here graphene plays key role in accelerating PFR by preventing recombination and facilitating the electron transfer process $[43,44]$. The main reasons for the superior visible light driven photocatalytic performance of $(\mathrm{CFO})_{1-\mathrm{x}}(\mathrm{GNPs})_{\mathrm{x}}$ nanocomposites can be attributed to the delayed recombination of charge carriers [45], satiable band gap[46], availability of more active sites, large surface area and accelerated PFR as result of GNPs addition [47]. The recombination dynamics of the photocatalyst can be understood based on photocatalytic quantum yield $\varphi$, given by the relationship[48]. 

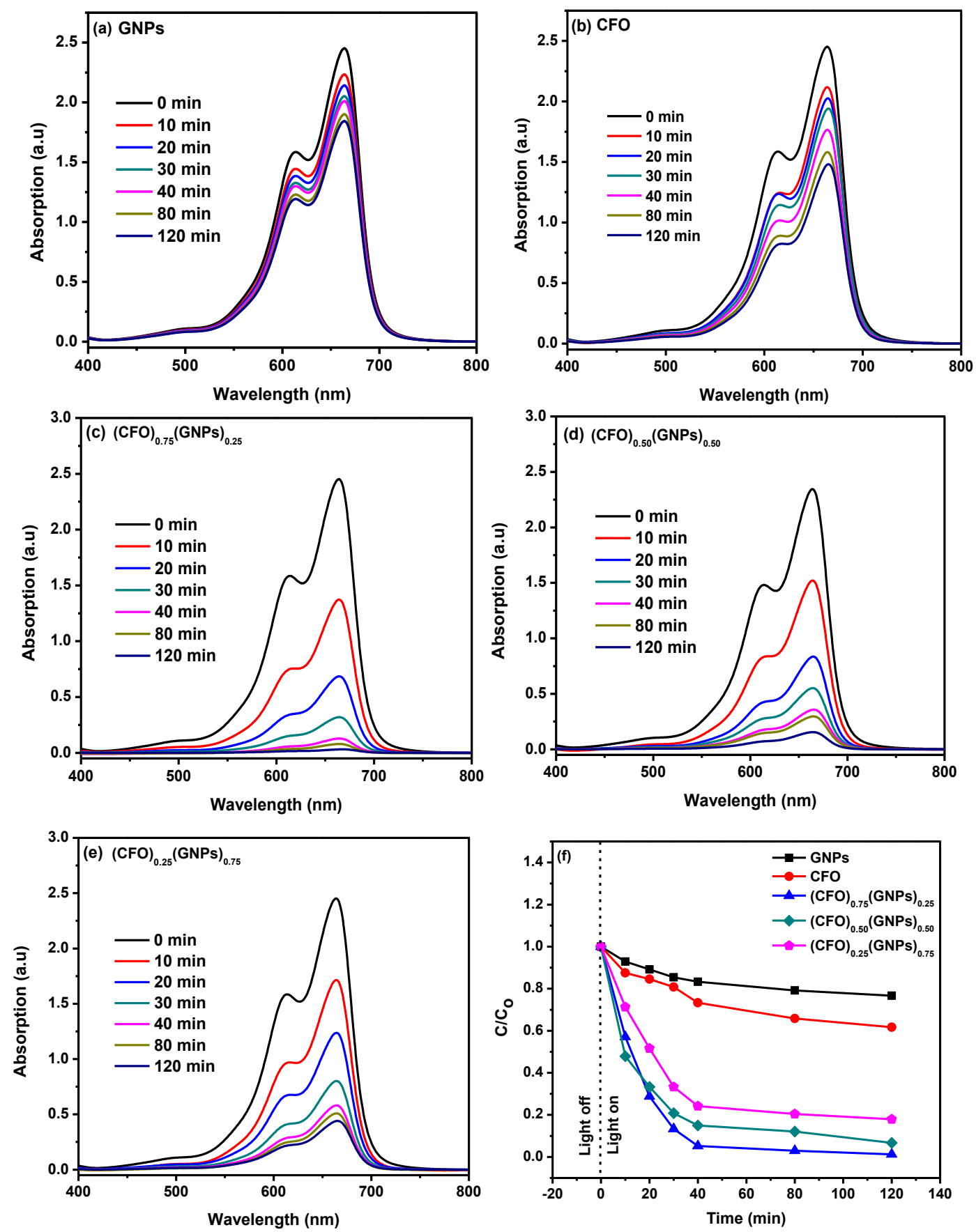

Fig. 7 (a)-(e) Absorption spectra of $\mathrm{MB}$ solution for $(\mathrm{CFO})_{1-\mathrm{x}}(\mathrm{GNPs})_{\mathrm{x}}$, and (f) photodegradation of $(\mathrm{CFO})_{1-\mathrm{x}}(\mathrm{GNPs})_{\mathrm{x}}$ nanocomposites

$$
\varphi \propto \frac{k_{c t}}{k_{c t}+k_{r}}
$$


Where, $k_{c t}$ denotes the rate of the charge transfer and $k_{r}$ is rate of recombination of the electronhole in a material. The relation clearly indicates that preventing recombination of the electrons and holes in a material under irradiation will play role for increasing the photocatalytic quantum yield of a material. Highly conducting and defects free GNPs support the charge transfer from CFO to GNPs which result the decrease in the recombination rate of $\mathrm{e}^{-/ h^{+}}$pair recombination rate and enhance improve photocatalytic activity performance of the nanocomposite nanocomposite samples [49, 50]. The prepared nanocomposites with optimum ratio of $25 \%$ GNPs having $98.7 \%$ degradation for MB are potential for purifications of textile waste water.

\section{Electrochemical Properties}

\subsection{Cyclic Voltmetery (CV)}

In order to explore the electrochemical efficiency of electrode based on prepared nanocomposites, the $\mathrm{CV}$ curves of $(\mathrm{CFO})_{1-\mathrm{x}}(\mathrm{GNPs})_{\mathrm{x}}$ have been measured at room temperature using $\mathrm{K}_{2} \mathrm{SO}_{4}$ electrolytes with two electrodes symmetric cell at different scan rates and typical plots for $\mathrm{x}=0,0.25,1$ are shown in Fig.8 (a)-(c). 

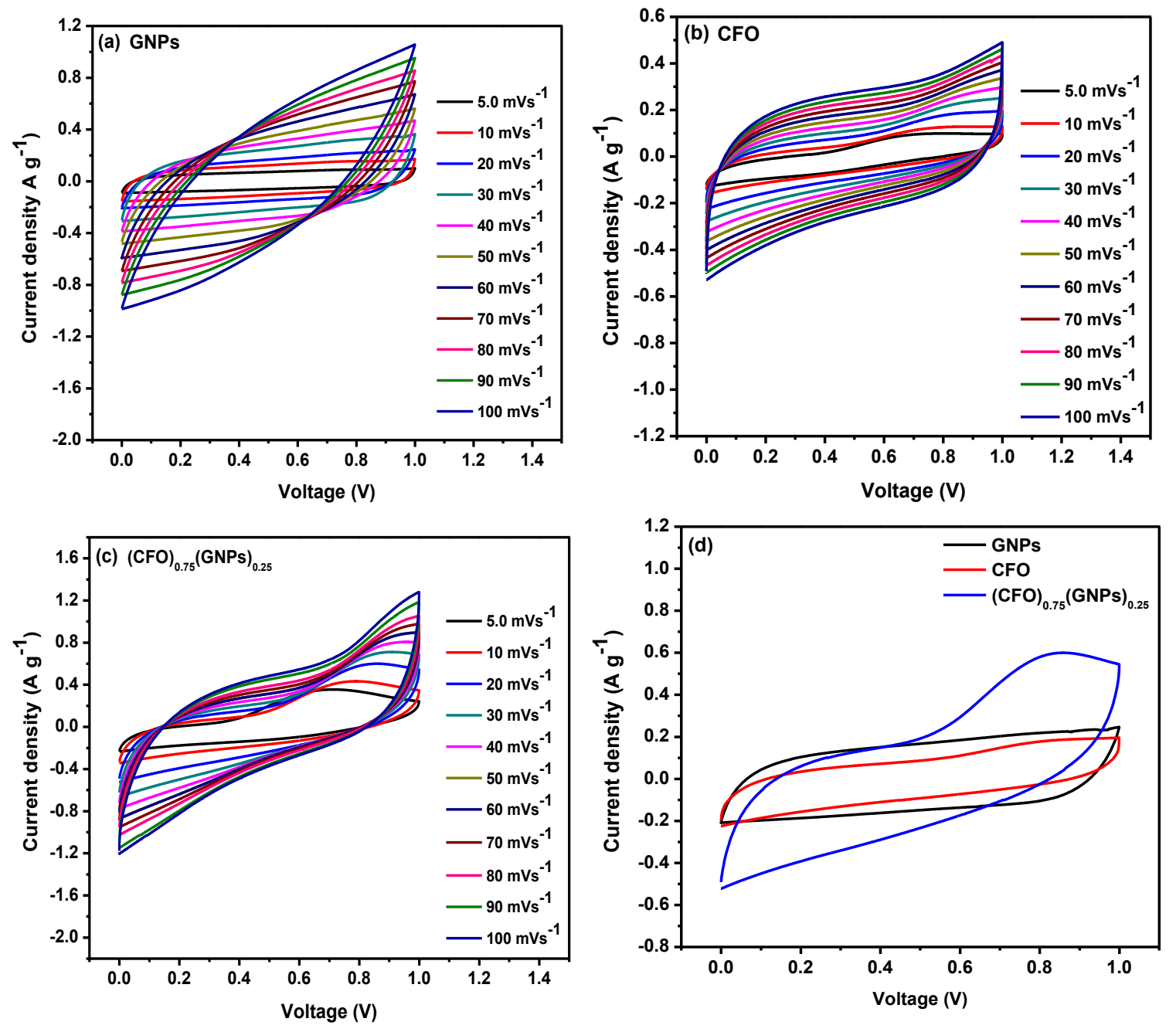

Fig. 8: (a)-(c) $\mathrm{CV}$ curves of the $(\mathrm{CFO})_{1-\mathrm{x}}(\mathrm{GNPs})_{\mathrm{x}}$ electrodes at various scan rates, (d) comparison of $\mathrm{CV}$ curves of $(\mathrm{CFO})_{1-\mathrm{x}}(\mathrm{GNPs})_{\mathrm{x}}$ electrodes at $20 \mathrm{mVs}^{-1}$

It is interestingly seen that the CV plots for both CFO and (CFO) ${ }_{0.75}(\mathrm{GNPs})_{0.25}$ exhibit sufficiently different shape then the rectangular shape observed for GNPs which suggest that there is pseudocapacitive contribution to the specific capacitance arising from Faradic redox reactions (FRR) [51]. It is clear from the Fig.8 (a)-(c) that the current response increases rises with the increase in scan rate for all samples. This increasing trend in current response is because of scan rate on the diffusion and migration of electrolyte ions electrolyte ions migration and diffusion. At relatively small scan rate, the flux of electrolyte ions the electrolyte ions flux is limited by the formation coating of thick diffusion layer on the surface of electrode the electrode surface, due to which the current response lowers. On the other hand, at higher scan rate, the flux 
of electrolyte is enhanced towards the electrodes, because the high scan rate prevents the growth of thick diffusion layer and as a result current response is seemed to be increased[52]. The typical comparison of CV plots of GNPs, CFO and $(\mathrm{CFO})_{0.75} \mathrm{GNPs}_{0.25}$ basedelectrodes at $20 \mathrm{mVs}^{-}$ ${ }^{1}$ are shown in Fig.8 (d). It is very remarkable to note that the integrated area of CV curve for $(\mathrm{CFO})_{0.75} \mathrm{GNPs}_{0.25}$ based electrode is significantly larger than individual CFO and GNPs based electrodes, indicating superior super-capacitive characteristics of the nanocomposite electrode. This excellent electrochemical performance of $(\mathrm{CFO})_{0.75} \mathrm{GNPs}_{0.25}$ is attributed to high electrical eenductivity conduction, high enhanced specific surface area and efficient charge transfer at electrode/electrolyte interface as result of GNPs addition in CFO [53].

\subsection{Galvanostatic charge/discharge (GCD) analysis}

To know the electrochemical performance of the electrodes based on $(\mathrm{CFO})_{1-\mathrm{x}}(\mathrm{GNPs})_{\mathrm{x}}$ nanocomposites, the GCD measurements at room temperature have been carried out. The specific capacitance of single electrode at various current densities has been calculated from the discharging portion of GCD curves using the following relation [54],

$$
\mathrm{C}_{\mathrm{s}}=\frac{4 I \Delta t}{m \Delta V}=4 C_{T}
$$

Where, $\Delta t, I, \Delta V, \mathrm{~m}$ and $C_{T}$ are the discharge time (s) time of discharge (s), current (A), applied potential, total mass of the active material in both electrodes (g) sum of active material mass in both of the electrodes (g) and capacitance of the cell respectively. Fig.9 (a)-(c) shows the typical GCD curves for CFO, GNPs and (CFO) ${ }_{0.75}(\mathrm{GNPs})_{0.25}$ electrodes in $0.5 \mathrm{M} \mathrm{K} \mathrm{K}_{2} \mathrm{SO}_{4}$ electrolyte under varying current densities. 



Fig. 9: (a-c) GDC curves of the $(\mathrm{CFO})_{1-\mathrm{x}}(\mathrm{GNPs})_{\mathrm{x}}$ electrodes at various scan rate (d) comparison of GDC curves of $(\mathrm{CFO})_{1-\mathrm{x}}(\mathrm{GNPs})_{\mathrm{x}}$ electrodes at $0.5 \mathrm{Ag}^{-1}$.

It can be observed that GCD curves of $\mathrm{CFO}$ and $\mathrm{CFO}_{0.75} \mathrm{GNPs}_{0.25}$ electrodes depict typical battery-like pseudocapacitive character compare to GNPs electrode having double layer capacitive behavior [55]. The GCD curves having symmetric nature for $(\mathrm{CFO})_{0.75}(\mathrm{GNPs})_{0.25}$ clearly depict that nanocomposites have high rate performance as electrode materials compared with individual components. Typical comparison plots of GCD curves under $0.5 \mathrm{Ag}^{-1}$ for GNPs, $\mathrm{CFO}$ and $\mathrm{CFO})_{0.75}(\mathrm{GNPs})_{0.25}$ electrode are displayed in Fig.9(d). The specific capacitance was calculated to be $82 \mathrm{Fg}^{-1}, 73 \mathrm{Fg}^{-1}$ and $227 \mathrm{Fg}^{-1}$ for GNPs, CFO and CFO) $0.75(\mathrm{GNPs})_{0.25}$ electrode at $0.5 \mathrm{Ag}^{-1}$ respectively. It can be inferred from the obtained results that the supercapacitance of the 
nanocomposite electrode is much higher than that of individual GNPs and CFO based electrodes. Fig. 10(a) shows the change in specific eapacitance capacity with increasing growing current density. It can be seen from Fig. 10(a) that the nanocomposite electrode retains relatively larger higher specific capacitance even at high large current density as compared to neat GNPs and CFO based electrodes, suggesting its higher rate capability. The superior electrochemical performance efficiency of the prepared nanocomposite electrode might be due to because of the lower degree of aggregation and higher conductivity of the CFO nanostructures.
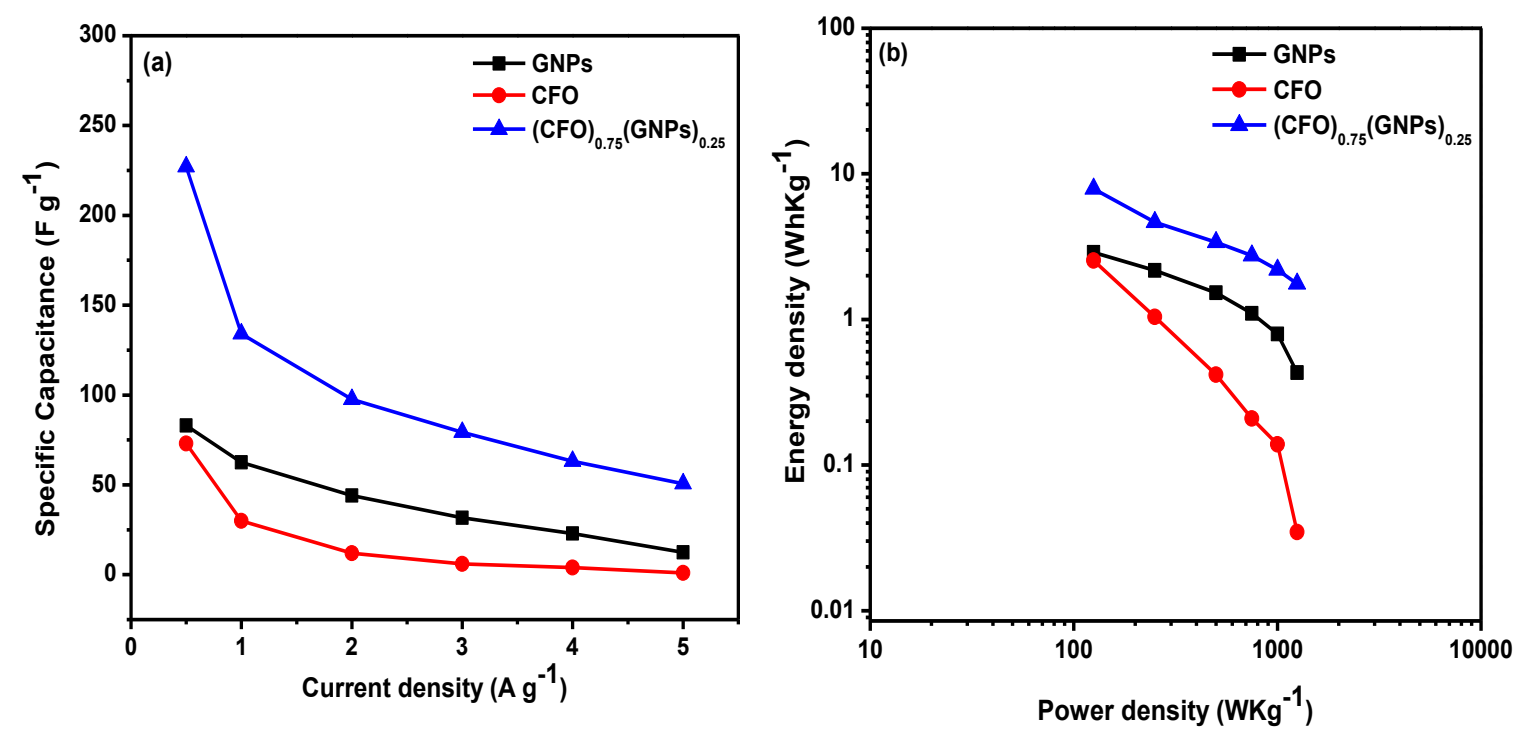

Fig. 10: (a) Specific capacitance curves of $(\mathrm{CFO})_{1-\mathrm{x}}(\mathrm{GNPs})_{\mathrm{x}}$ electrodes at various current densities (b) Ragone plots of $(\mathrm{CFO})_{1-\mathrm{x}}(\mathrm{GNPs})_{\mathrm{x}}$ electrodes.

\subsection{Energy density and Power Density}

It is well known that materials with having both high energy density and high power density both high energy and high-power density could meet the fundamental requirements of storage devices. The energy density and power density of a supereapacitor cell energy and power density of a electrochemical supercapacitor device has been calculated using the following equations [56]:

$$
\begin{aligned}
& E=\frac{0.5 \mathrm{C}_{\mathrm{T}}(\Delta V)^{2}}{3.6} \\
& P=\frac{E}{\Delta \mathrm{t}}
\end{aligned}
$$


Where $E, C_{\mp}, \Delta V, P, \Delta t$ are average energy density (Whkg ${ }^{-1}$ ), specific capacitance of the cell, potential window of discharge (V), power density $\left(\mathrm{Wkg}^{-1}\right)$ and discharge time (s). Where E, $\Delta V, C_{T}, P, \Delta t$ are average energy density $\left(\mathrm{Whkg}^{-1}\right)$, specific capacitance of the cell, potential window of discharge $(\mathrm{V})$, power density $\left(\mathrm{Wkg}^{-1}\right)$ and time of discharge (s). The energy density of the GNPs, CFO and CFO $)_{0.75}(\mathrm{GNPs})_{0.25}$ is observed to be $2.9 \mathrm{Whkg}^{-1}, 2.5 \mathrm{Whkg}^{-1}$ and $7.9 \mathrm{Whkg}^{-1}$ at $125 \mathrm{Wkg}^{-1}$ power density respectively. The Ragone plots results in Fig. 10(b) demonstrate that the energy density of $\mathrm{CFO})_{0.75}(\mathrm{GNPs})_{0.25}$ electrode is much higher than the GNPs and CFO based electrode. This high energy density of CFO-GNPs composites as compare to only CFO can be ascribed to its higher specific capacitance arising from the synergistic contribution of ECDL and pseudocapacitance [57, 58].

\subsection{Electrochemical Impedance Spectroscopy (EIS)}

The electrical conductivity and charge transfer characteristics at electrode/electrolyte interface $\mathrm{CFO})_{1-\mathrm{x}}(\mathrm{GNPs})_{\mathrm{x}}$ samples are checked using EIS measurements in the frequency range $0.1 \mathrm{~Hz}-100 \mathrm{kHz}$. EIS plots of $(\mathrm{CFO})_{1-\mathrm{x}}(\mathrm{GNPs})_{\mathrm{x}}$ nanocomposites show a straight line linear portion in the low frequency range in the region of low frequency and a semicircle are semicircular portion in the region of high frequency high frequency region as shown in Figure 11. The $X$-intercept $\left(Z^{\prime}\right)$ of the semicircular part indicates the intrinsic resistance within the electrochemical cell, which is combination of three types of resistances: i) electrolyte's ionic resistance ii) inherent resistance of the material in electrode iii) resistance originated from the contact between current collector and electrode. The radius of the semicircle signifies the resistance to charge transfer at the electrode/electrolyte interface [59]. 


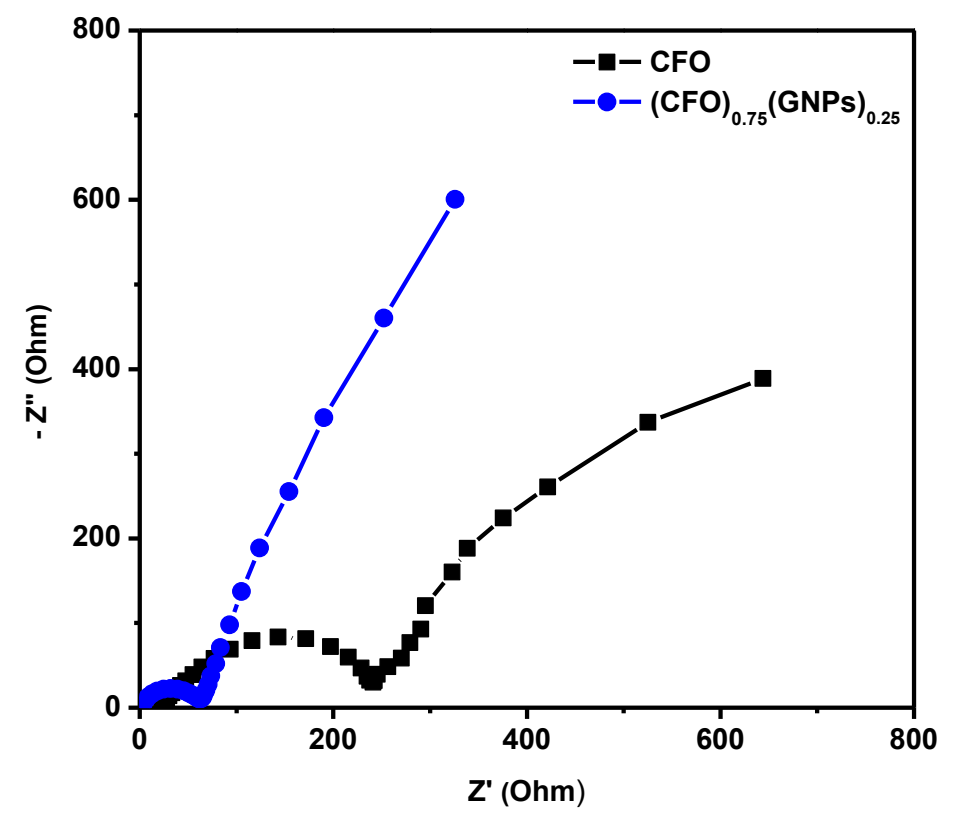

Fig. 11: EIS spectra of $(\mathrm{CFO})_{1-x}(\mathrm{GNPs})_{x}$ electrodes in frequency range $100 \mathrm{kHz}-0.1 \mathrm{~Hz}$

It is clear from the figure that the radius of semicircular portion of impedance spectra for CFO) 0.75 (GNPs) 0.25 is smaller than the CFO sample. This implies that the resistance to the interfacial charge transfer for $\mathrm{CFO})_{0.75}(\mathrm{GNPs})_{0.25}$ is smaller than the CFO electrode. It is also noted that the slope of the line in Nyquist plots is more vertical in case of CFO) $0.75(\mathrm{GNPs})_{0.25}$ as compared to neat $\mathrm{CFO}$, which is a manifestation of low diffusive resistance. This significant decrease in resistance to charge transfer of the $\mathrm{CFO})_{0.75}(\mathrm{GNPs})_{0.25}$ can be attributed to the high conductivity of GNPs component present in the nanocomposites.

\subsection{Cyclic performance and Columbic efficiency}

The eyclic cycling performance stability and Columbic efficiency of supercapacitors are key factors for their practical use in energy storage devices[60]. The cycling stability tests have been performed by GCD over 2000 cycles. Fig. 12 shows capacitive retention and Columbic efficiency of the (CFO) $)_{0.75}(\mathrm{GNPs})_{0.25}$ electrode at $5 \mathrm{Ag}^{-1}$. The results demonstrate that $72 \%$ of the initial specific capacitance is retained after 2000 continuous cycles, whereas the device has constant Columbic efficiency of $94 \%$. This outstanding cyclic stability achievement could be ascribed to the prevention of aggregation of CFO nanostructures during charge-discharge as 
well as the formation establishment of $\mathrm{Fe}-\mathrm{O}-\mathrm{C}$ and $\mathrm{Co}-\mathrm{O}-\mathrm{C}$ chemical bonds in the $(\mathrm{CFO})_{0.75}(\mathrm{GNPs})_{0.25}$ nanocomposites [61].

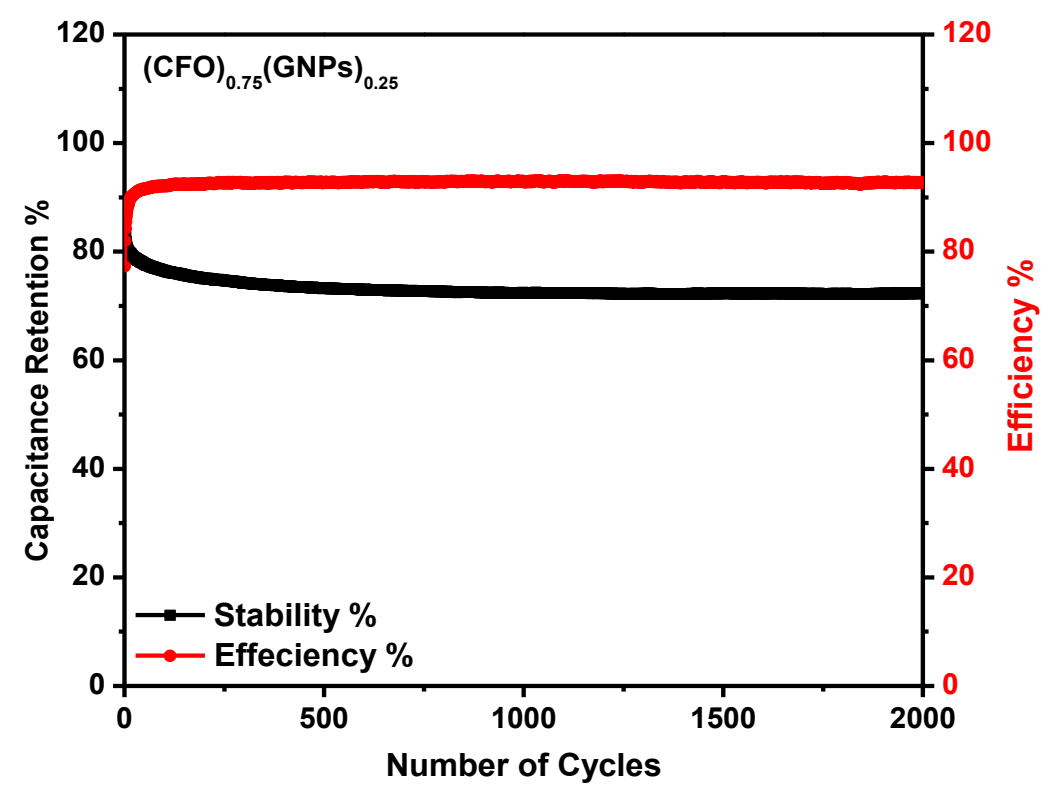

Fig.12: Cycling stability and efficiency of $(\mathrm{CFO})_{1-\mathrm{x}}(\mathrm{GNPs})_{\mathrm{x}}$ electrodes

\section{Conclusion}

A series of $(\mathrm{CFO})_{1-\mathrm{x}}(\mathrm{GNPs})_{\mathrm{x}}$ nanocomposites have been prepared through simple ecofriendly chemical method. GNPs induced enhancement in photocatalytic and electrochemical characteristics of prepared nanocomposites have been tailored and explored. All composites have shown significant photocatalytic activities, however the (CFO) $)_{0.75}(\mathrm{GNPs})_{0.25}$ nanocomposite has been found to be an excellent photocatalyst among them by degrading $98.51 \%$ of MB within 120 minutes via visible light driven photo Fenton reaction. This dye degradation performance is attributed towards high specific area, improved interfacial charge transfer, GNPs promoted charge carrier separation, and photo Fenton reaction. It has been also found that this particular $(\mathrm{CFO})_{0.75}$ (GNPs) $)_{0.25}$ nanocomposite has better electrochemical specific capacitance $\left(227 \mathrm{Fg}^{-1}\right.$ at 0.5 $\mathrm{Ag}^{-1}$ ) and outstanding stability (72\% capacitance retention) after 2000 cycles. The improved electrochemical performance and cycling stability of $(\mathrm{CFO})_{0.75}(\mathrm{GNPs})_{0.25}$ electrodes can be attributed to the prevented the agglomeration of CFO nanostructures, improved eharge transfer transfer of charge at the interface of the electrode/electrolyte interface and mechanical integrity 
provided by GNPs. These findings recommend that $(\mathrm{CFO})_{1-\mathrm{x}}(\mathrm{GNPs})_{\mathrm{x}}$ nanocomposites can used in cost-effective water purification technologies and electrochemical energy storage nanodevices.

\section{Acknowledgements}

This work was funded by Higher Education Commission of Pakistan (HEC) via NRPU (Grant No: 20-4861/R \& D/ HEC/14) and HEC-IRSIP (Grant No: 1-8/HEC/HRD/2017/8412 PIN: RSIP 39PSc15. The gratitude is also extended to Daniel Rueda García and Bhawna Nagar, Catalan Institute of Nanoscience and Nanotechnology (ICN2), Spain for the useful discussions.

\section{References}

[1] D. Lu, Y. Zhang, S. Lin, L. Wang, C. Wang, Synthesis of magnetic ZnFe2O4/graphene composite and its application in photocatalytic degradation of dyes, Journal of Alloys and Compounds 579 (2013) 336-342.

[2] A. Mukherjee, S. Chakrabarty, N. Kumari, W.-N. Su, S. Basu, Visible-Light-Mediated Electrocatalytic Activity in Reduced Graphene Oxide-Supported Bismuth Ferrite, ACS omega 3(6) (2018) 5946-5957.

[3] Y. Fu, Q. Chen, M. He, Y. Wan, X. Sun, H. Xia, X. Wang, Copper ferrite-graphene hybrid: a multifunctional heteroarchitecture for photocatalysis and energy storage, Industrial \& Engineering Chemistry Research 51(36) (2012) 11700-11709.

[4] P.T.L. Huong, N. Tu, H. Lan, N. Van Quy, P.A. Tuan, N.X. Dinh, V.N. Phan, A.-T. Le, Functional manganese ferrite/graphene oxide nanocomposites: effects of graphene oxide on the adsorption mechanisms of organic $\mathrm{MB}$ dye and inorganic As (v) ions from aqueous solution, RSC Advances 8(22) (2018) 12376-12389.

[5] M. Basith, R. Ahsan, I. Zarin, M. Jalil, Enhanced photocatalytic dye degradation and hydrogen production ability of $\mathrm{Bi} 25 \mathrm{FeO} 40-\mathrm{rGO}$ nanocomposite and mechanism insight, Scientific reports 8(1) (2018) 11090.

[6] J. Liang, Y. Wei, J. Zhang, Y. Yao, G. He, B. Tang, H. Chen, Scalable green method to fabricate magnetically separable NiFe2O4-Reduced Graphene Oxide nanocomposites with enhanced photocatalytic performance driven by visible light, Industrial \& Engineering Chemistry Research 57(12) (2018) 4311-4319.

[7] K.M. Rezaul Karim, M. Tarek, H.R. Ong, H. Abdullah, A. Yousuf, C.K. Cheng, M.M.R. Khan, Photoelectrocatalytic Reduction of Carbon Dioxide to Methanol using CuFe2O4 Modified with Graphene Oxide under Visible Light Irradiation, Industrial \& Engineering Chemistry Research (2018).

[8] C.M. Park, Y.M. Kim, K.-H. Kim, D. Wang, C. Su, Y. Yoon, Potential utility of graphenebased nano spinel ferrites as adsorbent and photocatalyst for removing organic/inorganic contaminants from aqueous solutions: A mini review, Chemosphere (2019).

[9] Y. Yao, J. Qin, Y. Cai, F. Wei, F. Lu, S. Wang, Facile synthesis of magnetic ZnFe 2 O 4reduced graphene oxide hybrid and its photo-Fenton-like behavior under visible iradiation, Environmental Science and Pollution Research 21(12) (2014) 7296-7306.

[10] C. Xu, J. Zhu, R. Yuan, X. Fu, More effective use of graphene in photocatalysis by conformal attachment of small sheets to TiO2 spheres, Carbon 96 (2016) 394-402. 
[11] A. Arshad, J. Iqbal, I. Ahmad, M. Israr, Graphene/Fe3O4 nanocomposite: Interplay between photo-Fenton type reaction, and carbon purity for the removal of methyl orange, Ceramics International 44(3) (2018) 2643-2648.

[12] L. Su, S. Lei, L. Liu, L. Liu, Y. Zhang, S. Shi, X.J.J.o.M.C.A. Yan, Sprinkling MnFe 2 O 4 quantum dots on nitrogen-doped graphene sheets: the formation mechanism and application for high-performance supercapacitor electrodes, 6(21) (2018) 9997-10007.

[13] Y.-P. Gao, Z.-B. Zhai, Q.-Q. Wang, Z.-Q. Hou, K.-J.J.J.o.c. Huang, i. science, Cycling profile of layered $\mathrm{MgAl} 2 \mathrm{O} 4 /$ reduced graphene oxide composite for asymmetrical supercapacitor, Journal of Colloid and Interface Science 539 (2019) 38-44.

[14] J. Fang, X. Zhang, X. Miao, Y. Liu, S. Chen, Y. Chen, J. Cheng, W. Wang, Y. Zhang, A phenylenediamine-mediated organic electrolyte for high performance graphene-hydrogel based supercapacitors, Electrochimica Acta 273 (2018) 495-501.

[15] L. Yue, S. Zhang, H. Zhao, Y. Feng, M. Wang, L. An, X. Zhang, J. Mi, One-pot synthesis $\mathrm{CoFe} 2 \mathrm{O} 4 / \mathrm{CNTs}$ composite for asymmetric supercapacitor electrode, Solid State Ionics 329 (2019) 15-24.

[16] X. Zhang, M. Zhu, T. Ouyang, Y. Chen, J. Yan, K. Zhu, K. Ye, G. Wang, K. Cheng, D. $\mathrm{Cao}, \mathrm{NiFe} 2 \mathrm{O} 4$ nanocubes anchored on reduced graphene oxide cryogel to achieve a $1.8 \mathrm{~V}$ flexible solid-state symmetric supercapacitor, Chemical Engineering Journal 360 (2019) 171179.

[17] L. Li, H. Bi, S. Gai, F. He, P. Gao, Y. Dai, X. Zhang, D. Yang, M. Zhang, P. Yang, Uniformly dispersed $\mathrm{ZnFe} 2 \mathrm{O} 4$ nanoparticles on nitrogen-modified graphene for highperformance supercapacitor as electrode, Scientific reports 7 (2017) 43116.

[18] A. Allahbakhsh, M. Arjmand, Graphene-based phase change composites for energy harvesting and storage: State of the art and future prospects, Carbon 148 (2019) 441-480.

[19] Y. Wu, J. Zhu, L. Huang, A review of three-dimensional graphene-based materials: Synthesis and applications to energy conversion/storage and environment, Carbon 143 (2019) 610-640.

[20] C. Nordhei, A.L. Ramstad, D.G. Nicholson, Nanophase cobalt, nickel and zinc ferrites: synchrotron XAS study on the crystallite size dependence of metal distribution, Physical Chemistry Chemical Physics 10(7) (2008) 1053-1066.

[21] Y. Xiao, X. Li, J. Zai, K. Wang, Y. Gong, B. Li, Q. Han, X. Qian, CoFe 2 O 4-graphene nanocomposites synthesized through an ultrasonic method with enhanced performances as anode materials for Li-ion batteries, Nano-micro letters 6(4) (2014) 307-315.

[22] H.-Y. He, J. Lu, Highly photocatalytic activities of magnetically separable reduced graphene oxide-CoFe2O4 hybrid nanostructures in dye photodegradation, Separation and Purification Technology 172 (2017) 374-381.

[23] H. Zhang, C. Zhai, J. Wu, X. Ma, D. Yang, Cobalt ferrite nanorings: Ostwald ripening dictated synthesis and magnetic properties, Chemical Communications (43) (2008) 5648-5650.

[24] J. Mohapatra, A. Mitra, D. Bahadur, M. Aslam, Surface controlled synthesis of MFe 2 O 4 $(\mathrm{M}=\mathrm{Mn}, \mathrm{Fe}, \mathrm{Co}, \mathrm{Ni}$ and $\mathrm{Zn})$ nanoparticles and their magnetic characteristics, CrystEngComm 15(3) (2013) 524-532.

[25] Y. Gong, D. Li, Q. Fu, C. Pan, Influence of graphene microstructures on electrochemical performance for supercapacitors, Progress in Natural Science: Materials International 25(5) (2015) 379-385. 
[26] A.K. Das, S. Maiti, B. Khatua, High performance electrode material prepared through insitu polymerization of aniline in the presence of zinc acetate and graphene nanoplatelets for supercapacitor application, Journal of Electroanalytical Chemistry 739 (2015) 10-19.

[27] H. Xia, D. Zhu, Y. Fu, X. Wang, CoFe2O4-graphene nanocomposite as a high-capacity anode material for lithium-ion batteries, Electrochimica Acta 83 (2012) 166-174.

[28] M. Zhang, X. Yang, X. Kan, X. Wang, L. Ma, M. Jia, Carbon-encapsulated CoFe2O4/graphene nanocomposite as high performance anode for lithium ion batteries, Electrochimica Acta 112 (2013) 727-734.

[29] T. Yamashita, P. Hayes, Analysis of XPS spectra of $\mathrm{Fe} 2+$ and $\mathrm{Fe} 3+$ ions in oxide materials, Applied surface science 254(8) (2008) 2441-2449.

[30] X.F. Lu, L.F. Gu, J.W. Wang, J.X. Wu, P.Q. Liao, G.R. Li, Bimetal-organic framework derived $\mathrm{CoFe} 2 \mathrm{O} 4 / \mathrm{C}$ porous hybrid nanorod arrays as high-performance electrocatalysts for oxygen evolution reaction, Advanced Materials 29(3) (2017) 1604437.

[31] J. Zhao, Y. Yang, X. Dong, Q. Ma, W. Yu, J. Wang, G. Liu, Electrospinning construction of Bi 2 WO 6/RGO composite nanofibers with significantly enhanced photocatalytic water splitting activity, RSC Advances 6(69) (2016) 64741-64748.

[32] H. Estrade-Szwarckopf, XPS photoemission in carbonaceous materials: A "defect" peak beside the graphitic asymmetric peak, Carbon 42(8-9) (2004) 1713-1721.

[33] A. Arshad, J. Iqbal, Q. Mansoor, NiO-nanoflakes grafted graphene: an excellent photocatalyst and a novel nanomaterial for achieving complete pathogen control, Nanoscale 9(42) (2017) 16321-16328.

[34] L. He, L. Jing, Y. Luan, L. Wang, H. Fu, Enhanced visible activities of $\alpha-\mathrm{Fe} 2 \mathrm{O} 3$ by coupling N-doped graphene and mechanism insight, ACS Catalysis 4(3) (2014) 990-998.

[35] M.M. Mohamed, I. Ibrahim, T.M. Salama, Rational design of manganese ferrite-graphene hybrid photocatalysts: efficient water splitting and effective elimination of organic pollutants, Applied Catalysis A: General 524 (2016) 182-191.

[36] L.G. Devi, M. Srinivas, Hydrothermal synthesis of reduced graphene oxide-CoFe2O4 heteroarchitecture for high visible light photocatalytic activity: Exploration of efficiency, stability and mechanistic pathways, Journal of environmental chemical engineering 5(4) (2017) 3243-3255.

[37] F. Soofivand, M. Salavati-Niasari, Co 3 O 4/graphene nanocomposite: pre-graphenization synthesis and photocatalytic investigation of various magnetic nanostructures, RSC Advances 5(79) (2015) 64346-64353.

[38] X. Tang, Z. Zu, Z. Zang, Z. Hu, W. Hu, Z. Yao, W. Chen, S. Li, S. Han, M. Zhou, $\mathrm{CsPbBr} 3 /$ Reduced Graphene Oxide nanocomposites and their enhanced photoelectric detection application, Sensors and Actuators B: Chemical 245 (2017) 435-440.

[39] H. Zhang, X. Lv, Y. Li, Y. Wang, J. Li, P25-graphene composite as a high performance photocatalyst, ACS nano 4(1) (2009) 380-386.

[40] Y. Zhang, N. Zhang, Z.-R. Tang, Y.-J.J.P.C.C.P. Xu, Improving the photocatalytic performance of graphene-TiO 2 nanocomposites via a combined strategy of decreasing defects of graphene and increasing interfacial contact, Physical Chemistry Chemical Physics 14(25) (2012) 9167-9175.

[41] M. Su, C. He, V.K. Sharma, M.A. Asi, D. Xia, X.-z. Li, H. Deng, Y. Xiong, Mesoporous zinc ferrite: synthesis, characterization, and photocatalytic activity with $\mathrm{H} 2 \mathrm{O} 2$ /visible light, Journal of hazardous materials 211 (2012) 95-103. 
[42] C. Ponraj, G. Vinitha, J. Daniel, A review on the visible light active BiFeO3 nanostructures as suitable photocatalyst in the degradation of different textile dyes, Environmental Nanotechnology, Monitoring \& Management 7 (2017) 110-120.

[43] Y. Fu, X. Wang, Magnetically separable $\mathrm{ZnFe} 2 \mathrm{O} 4$-graphene catalyst and its high photocatalytic performance under visible light irradiation, Industrial \& Engineering Chemistry Research 50(12) (2011) 7210-7218.

[44] N.A. Zubir, C. Yacou, J. Motuzas, X. Zhang, X.S. Zhao, J.C.D. da Costa, The sacrificial role of graphene oxide in stabilising a Fenton-like catalyst GO-Fe 30 4, Chemical Communications 51(45) (2015) 9291-9293.

[45] L. Chen, S. Yang, L. Mu, P.-C.J.J.o.c. Ma, i. science, Three-dimensional titanium dioxide/graphene hybrids with improved performance for photocatalysis and energy storage, Journal of Colloid and Interface Science 512 (2018) 647-656.

[46] M. Sundararajan, L.J. Kennedy, P. Nithya, J.J. Vijaya, M.J.J.o.P. Bououdina, C.o. Solids, Visible light driven photocatalytic degradation of rhodamine B using $\mathrm{Mg}$ doped cobalt ferrite spinel nanoparticles synthesized by microwave combustion method, 108 (2017) 61-75.

[47] K.K. Haldar, G. Sinha, J. Lahtinen, A. Patra, Hybrid colloidal Au-CdSe pentapod heterostructures synthesis and their photocatalytic properties, ACS applied materials \& interfaces 4(11) (2012) 6266-6272.

[48] N. Yang, Y. Liu, H. Wen, Z. Tang, H. Zhao, Y. Li, D.J.A.N. Wang, Photocatalytic properties of graphdiyne and graphene modified TiO2: from theory to experiment, 7(2) (2013) 1504-1512.

[49] J. Liu, L. Liu, H. Bai, Y. Wang, D.D. Sun, Gram-scale production of graphene oxide-TiO2 nanorod composites: towards high-activity photocatalytic materials, Applied Catalysis B: Environmental 106(1-2) (2011) 76-82.

[50] T.-D. Nguyen-Phan, V.H. Pham, E.W. Shin, H.-D. Pham, S. Kim, J.S. Chung, E.J. Kim, S.H. Hur, The role of graphene oxide content on the adsorption-enhanced photocatalysis of titanium dioxide/graphene oxide composites, Chemical Engineering Journal 170(1) (2011) 226232.

[51] S.M. Alshehri, J. Ahmed, A.N. Alhabarah, T. Ahamad, T. Ahmad, Nitrogen-Doped Cobalt Ferrite/Carbon Nanocomposites for Supercapacitor Applications, ChemElectroChem 4(11) (2017) 2952-2958.

[52] M. Alam, K. Karmakar, M. Pal, K. Mandal, Electrochemical supercapacitor based on double perovskite Y 2 NiMnO 6 nanowires, RSC Advances 6(115) (2016) 114722-114726.

[53] J. Choi, K.-d. Seong, J. Kang, M. Hwang, J.M. Kim, X. Jin, Y. Piao, Fluoride ion-mediated morphology control of fluorine-doped $\mathrm{CoFe} 2 \mathrm{O}$ 4/graphene sheet composites for hybrid supercapacitors with enhanced performance, Electrochimica Acta 279 (2018) 241-249.

[54] D. Zha, P. Xiong, X. Wang, Strongly coupled manganese ferrite/carbon black/polyaniline hybrid for low-cost supercapacitors with high rate capability, Electrochimica Acta 185 (2015) 218-228.

[55] D. Maruthamani, S. Vadivel, M. Kumaravel, B. Saravanakumar, B. Paul, S.S. Dhar, A. Habibi-Yangjeh, A. Manikandan, G.J.J.o.c. Ramadoss, i. science, Fine cutting edge shaped Bi2O3rods/reduced graphene oxide (RGO) composite for supercapacitor and visible-light photocatalytic applications, Journal of Colloid and Interface Science 498 (2017) 449-459.

[56] J. Zhang, J. Jiang, H. Li, X. Zhao, A high-performance asymmetric supercapacitor fabricated with graphene-based electrodes, Energy \& Environmental Science 4(10) (2011) 40094015 . 
[57] C. Liu, Z. Yu, D. Neff, A. Zhamu, B.Z. Jang, Graphene-based supercapacitor with an ultrahigh energy density, Nano letters 10(12) (2010) 4863-4868.

[58] J. Yan, T. Wei, B. Shao, Z. Fan, W. Qian, M. Zhang, F. Wei, Preparation of a graphene nanosheet/polyaniline composite with high specific capacitance, Carbon 48(2) (2010) 487-493.

[59] Y. Liu, X. Miao, J. Fang, X. Zhang, S. Chen, W. Li, W. Feng, Y. Chen, W. Wang, Y. Zhang, Layered-MnO2 nanosheet grown on nitrogen-doped graphene template as a composite cathode for flexible solid-state asymmetric supercapacitor, ACS applied materials \& interfaces 8(8) (2016) 5251-5260.

[60] S.I. Wong, J. Sunarso, B.T. Wong, H. Lin, A. Yu, B. Jia, Towards enhanced energy density of graphene-based supercapacitors: Current status, approaches, and future directions, Journal of Power Sources 396 (2018) 182-206.

[61] B. Liu, Y. Liu, H. Chen, M. Yang, H.J.A.S.C. Li, Engineering, MnO2 nanostructures deposited on graphene-like porous carbon nanosheets for high-rate performance and high-energy density asymmetric supercapacitors, ACS Sustainable Chemistry \& Engineering 7 (3) (2019) 3101-3110. 


\section{List of Figures}

Fig.1: XRD patterns of $(\mathrm{CFO})_{1-\mathrm{x}}-(\mathrm{GNPs})_{\mathrm{x}}$ samples

Fig.2: TEM micrographs of $(\mathrm{CFO})_{1-\mathrm{x}}(\mathrm{GNPs})_{\mathrm{x}}$ samples (inset: HRTEM image of CFO)

Fig.3: FTIR spectra of $(\mathrm{CFO})_{1-\mathrm{x}}(\mathrm{GNPs})_{\mathrm{x}}$ nanocomposites

Fig.4: XPS wide angle spectra for $(\mathrm{CFO})_{1-\mathrm{x}}(\mathrm{GNPs})_{\mathrm{x}}$ nanocomposites.

Fig.5: a) UV-vis absorbance spectra of (CFO) ${ }_{1-x}(\mathrm{GNPs})_{\mathrm{x}}$ nanocomposites b) Tauc's plots of $(\mathrm{CFO})_{1-\mathrm{x}}(\mathrm{GNPs})_{\mathrm{x}}$ nanocomposites.

Fig. 6: PL spectra of $(\mathrm{CFO})_{1-\mathrm{x}}(\mathrm{GNPs})_{\mathrm{x}}$ nanocomposites

Fig. 7: (a)-(e) Absorption spectra of MB solution for $(\mathrm{CFO})_{1-\mathrm{x}}(\mathrm{GNPs})_{\mathrm{x}}$, and (f) photodegradation of $(\mathrm{CFO})_{1-\mathrm{x}}(\mathrm{GNPs})_{\mathrm{x}}$ nanocomposites

Fig. 8: (a)-(c) $\mathrm{CV}$ curves of the $(\mathrm{CFO})_{1-\mathrm{x}}(\mathrm{GNPs})_{\mathrm{x}}$ electrodes at various scan rate, and (d) comparison of $\mathrm{CV}$ curves of $(\mathrm{CFO})_{1-\mathrm{x}}(\mathrm{GNPs})_{\mathrm{x}}$ electrodes at $20 \mathrm{mVs}^{-1}$

Fig. 9: (a)-(c) GDC curves of the $(\mathrm{CFO})_{1-x}(\mathrm{GNPs})_{\mathrm{x}}$ electrodes at various scan rate, and (d) comparison of GDC curves of $(\mathrm{CFO})_{1-\mathrm{x}}(\mathrm{GNPs})_{\mathrm{x}}$ electrodes at $0.5 \mathrm{Ag}^{-1}$.

Fig. 10:(a) Specific capacitance curves of $(\mathrm{CFO})_{1-x}(\mathrm{GNPs})_{\mathrm{x}}$ electrodes at various current densities

(b) Ragone plots of $(\mathrm{CFO})_{1-\mathrm{x}}(\mathrm{GNPs})_{\mathrm{x}}$ electrodes.

Fig. 11: EIS spectra of $(\mathrm{CFO})_{1-\mathrm{x}}(\mathrm{GNPs})_{\mathrm{x}}$ electrodes in frequency range $100 \mathrm{kHz}-0.1 \mathrm{~Hz}$

Fig.12: Cycling stability and efficiency of $(\mathrm{CFO})_{1-\mathrm{x}}(\mathrm{GNPs})_{\mathrm{x}}$ electrodes 